\title{
Normal Tissue Segment
}

National Cancer Institute

\section{Source}

National Cancer Institute. Normal Tissue Segment. NCI Thesaurus. Code C162623.

Sufficient total material from each patient, divided to yield a minimum of one aliquot, preferably divided into one to three aliquots of non-neoplastic ("normal") adjacent tissue (as feasible) suitable for processing for proteomic and genomic analysis. 